\title{
Development of Seismic-induced Fire Risk Assessment Method for a Building
}

\author{
AI SEKIZAWA \\ National Research Institute of Fire and Disaster \\ 3-14-1, Nakahara, Mitaka, Tokyo 181-8633, Japan \\ sekizawa@fri.go.jp
}

MANABU EBIHARA and HIROAKI NOTAKE

Izumi Research Institute, Shimizu Corporation

\begin{abstract}
Post-earthquake fire risk can be different from other design scenarios because fire protection systems can be non-functional even when a building itself is structurally sound. We have developed a prototype of a seismic-induced fire risk assessment method to evaluate fire risk based on factors such as size and type of buildings, installed fire protection systems, and the intensity of input earthquake motion. This paper describes the outline of the framework and examples of results from a case study applying a tentative simplified model. Results from our study show that sprinkler systems that are designed to be seismically resistant have a significant effect in mitigating fire risk associated with earthquakes.
\end{abstract}

KEYWORDS: Fire risk, fire risk assessment, post-earthquake fire, fire protection system

\section{Introduction}

To date, while a number of studies have been conducted on fire risk assessment for daily fires, there have been very few studies on fire risk assessment of a building at an earthquake. For one reason, the concern on fire problems at earthquakes has mainly focused on fire risks on a city area level such as number of fire ignitions and large-scale urban fires, so fire risk on a level of one building has been rarely discussed. However, at the 1995 Kobe earthquake, more than a few fires occurred in fire-resistive buildings as well as in wooden buildings. Also, various surveys have revealed that many fire protection systems, such as sprinkler systems, were damaged by earthquakes and lost their proper function because of mechanical failure and/or deformation by the earthquake motion, though otherwise they should have functioned $[1,2,3,4]$.

This study focuses on the issue that fire risk would be different from usual at an earthquake, because fire protection systems could be functionally no use even when a building itself has no problem in terms of structural damage. Therefore, it is very significant to develop seismic-induced fire risk assessment method in consideration of these possible difficulties in order to enable to evaluate fire risk according to the conditions such as size and type of buildings, installed fire protection systems as well as intensity of input earthquake motion. Furthermore, seismic-induced fire risk assessment method would be useful not only to evaluate present risks, but also to estimate how much the risk changes when fire protection systems are improved to be seismic-proof, and to find out effective countermeasures to reduce the risk. The purpose of this study is to develop the framework for seismic-induced fire risk assessment method for a building. In this paper, described are the outline of the 
framework and examples of results from a case study applying a tentative simplified model.

Damages to Fire Protection Systems in Past Earthquakes

At an earthquake situation, smooth emergency response to a fire in a building by fire brigades and/or security staff can not be expected like usual time because of lack of resources and personnel against simultaneous many fires. Considering this special condition at an earthquake, the reliability of installed fire protection systems, especially automatic fire suppression systems like a sprinkler is a very important issue.

Even before the 1995 Kobe earthquake, the Marine and Fire Insurance Association of Japan already recognized vulnerability of installed fire protection systems at an earthquake. And, they conducted the investigation study on the reliability of installed fire protection systems especially targeting at sprinkler systems based on the experiences in several past earthquakes including some earthquakes in the U.S. From the results of their investigations [1], it is reported that the percentages of damaged sprinkler systems among surveyed buildings were 34\% in the 1993 Kushiro-oki earthquake and $41 \%$ in the 1994 Sanriku-haruka-oki earthquake where the seismic intensity of both earthquakes were level 6 in JMA (Japan Meteorological Agency) scale that is about $250 \mathrm{~cm} / \mathrm{sec}^{2}$ to $400 \mathrm{~cm} / \mathrm{sec}^{2}$ in ground surface acceleration.

Also, Table 1 shows the data on percentages of damaged fire protection systems by type in Kobe City in the Kobe earthquake [2]. The seismic intensity in JMA scale was level 6 or level $7\left(250 \mathrm{~cm} / \mathrm{sec}^{2}\right.$ or more $)$ in Kobe. The percentage of damaged sprinkler system in Kobe City is $40.8 \%$ and that of fire doors is $30.7 \%$. These data indicate that sprinkler systems are very vulnerable to seismic motion even in case where the level of ground motion has resulted in little or no structural damage. On the other hand, there were 261 post-earthquake structure fires, $83(31.8 \%)$ of which started in fire resistive buildings such as reinforced concrete or steel frame construction and 76 fires $(29.1 \%)$ occurred in buildings 4 floors or more in height in the earthquake. Also, there were four fires from the buildings installed with sprinkler system, two of which resulted in spread fires with burned area of $3,600 \mathrm{~m}^{2}$ and $35 \mathrm{~m}^{2}$ because of no use of the sprinkler system.

Table 1 Damages to Fire Protection Systems in Kobe City.

*From the investigation report [2] on the 1995 Kobe earthquake by Kobe City Fire Department.

\begin{tabular}{|l|l|l|l|}
\hline $\begin{array}{l}\text { Type of fire } \\
\text { protection systems }\end{array}$ & $\begin{array}{l}\text { Number of systems } \\
\text { surveyed }\end{array}$ & $\begin{array}{l}\text { Number of } \\
\text { damaged systems }\end{array}$ & $\begin{array}{l}\text { Percentage (\%) of } \\
\text { damaged systems }\end{array}$ \\
\hline Sprinkler system & 544 & 222 & 40.8 \\
\hline Indoor fire hydrant & 451 & 107 & 23.7 \\
\hline $\begin{array}{l}\text { Foam } \\
\text { extinguishing } \\
\text { system }\end{array}$ & 83 & 20 & 24.1 \\
\hline $\begin{array}{l}\text { Halogenated } \\
\text { extinguishing } \\
\text { system }\end{array}$ & 162 & 17 & 10.5 \\
\hline $\begin{array}{l}\text { Automatic fire } \\
\text { alarm system }\end{array}$ & 542 & 109 & 20.1 \\
\hline $\begin{array}{l}\text { Emergency } \\
\text { generator unit }\end{array}$ & 444 & 71 & 16.0 \\
\hline Fire doors & 524 & 161 & 30.7 \\
\hline
\end{tabular}


The damage level of active and passive fire protection systems in a building is predictable by earthquake response of a building, which is determined by frequency characteristics of earthquake motion input to a building and the vibration property of a building itself. Therefore, if the size and type of structure of a building in a particular site as well as input earthquake motion are specified as input conditions, the damage level of active and passive fire protection systems can be estimated to a certain extent. In this study, peak ground acceleration is adopted as an index of input earthquake motion level. In addition to the above, we consider the condition of response action by security staff at a fire, which is also affected by the intensity of an earthquake.

To develop a seismic-induced fire risk assessment method, we incorporated the failure probability of active and passive fire protection systems caused by an earthquake, which is main contribution of this study, into the existing fire risk assessment method for usual fires [5]. First, we introduce a simplified model to estimate earthquake response of a building, which is the base for other models or estimation to predict the damage level of active and passive fire protection systems. Then, we construct the functional failure prediction model for sprinkler systems as a representative of active fire protection systems. However, since there is very little data available for constructing prediction models for damage level of elements of compartments such as walls and fire doors, we assume reducing ratio of fire resistance time of compartments based on the data in existing literature at present. Also, we tentatively assume the failure probability of response actions by security staff according to the intensity of input earthquake motion. After estimation of failure probability of active and passive fire protection systems, the fire risk assessment method to predict transition probability of fire phases and burned area on a given fire scenario is introduced to assess the potential fire risk of a building at an earthquake.

\section{Simplified Model to Estimate the Earthquake Response of a Building}

In this study, a simplified model to estimate structure responses is introduced on the premise that existing structures are designed under the current building codes. As for the first natural period $\left(\mathrm{T}_{1}\right)$, the following is generally given depending on the number of floors (N) by type of structure.

$$
\text { Reinforced concrete structure }: \mathrm{T}_{1}=0.053 \mathrm{~N}
$$

Steel frame structure $\quad: \mathrm{T}_{1}=0.079 \mathrm{~N}$

Then as for damping factor $(\mathrm{h})$, which are partly effected by dissipation damping to ground and/or histeresis damping relating to nonlinear vibration of structures themselves, the following is roughly given by type of structure.

$$
\text { Reinforced concrete structure }: \mathrm{h}=0.03 \sim 0.05
$$

$$
\text { Steel frame structure } \quad: \mathrm{h}=0.02 \sim 0.03
$$

By the way, acceleration response spectrum, $\mathrm{S}_{\mathrm{A}}(\mathrm{T}, \mathrm{h})$, is given with the following formula in "Hand Book for Loads on Buildings" [6] issued by Architectural Institute of Japan. 


$$
\begin{cases}S_{A}(T, h)=\left(1+\frac{f_{A}-1}{d} \frac{T}{T_{c}}\right) F_{h} G_{A} R_{A} A_{0} & , 0 \leq T \leq d T_{c} \\ S_{A}(T, h)=F_{h} f_{A} G_{A} R_{A} A_{0} & , d T_{c} \leq T \leq T_{c} \\ S_{A}(T, h)=\frac{2 \pi F_{h} f_{V} G_{V} R_{V} V_{0}}{T} & , T_{c} \leq T\end{cases}
$$

where,

$$
f_{A} \text { : The ratio of } S_{A}(T, 0.05) \text { to } G_{A} R_{A} A_{O} \quad\left(d T_{C} \leqq T \leqq T\right)
$$

$f_{V}$ : The ratio of $S_{V}(T, 0.05)=S_{A}(T, 0.05) \times T /(2 \pi)$ to $G_{V} R_{V} A_{0} \quad\left(T_{C} \leqq T\right)$

$d$ : The ratio of the minimum period to the maximum period where $S_{A}(T, h)$ is constant.

$T_{C}$ : The maximum period given by the following formula where $S_{A}(T, h)$ is constant.[sec]

$$
T_{c}=\frac{2 \pi f_{V} G_{V} R_{V} V_{0}}{f_{A} G_{A} R_{A} A_{0}}
$$

$\mathrm{A}_{0}$ : 100-year expectancy of peak ground acceleration depending on respective soil-types.

(Soil-type I: hard soil, soil-type II: soil of alluvial deposit, soil-type III: soft soil)

$V_{0}: 100$-year expectancy of peak ground velocity depending on respective soil-types.

$R_{A}$ : Return period modification coefficient for peak ground acceleration. [sec]

$R_{V}$ : Return period modification coefficient of peak ground velocity. [sec]

$G_{A}$ : Soil-type coefficient for peak ground acceleration.

(1.0 for soil-type I and 1.2 for soil-type II and III)

$G_{V}$ : Soil-type coefficient for peak ground velocity.

(1.0 for soil-type I and 2.0 for soil-type II, and 3.0 for soil-type III)

$F_{h}$ : Coefficient for damping ratio.

$S_{V}(T, h)=S_{A}(T, h) \times T /(2 \pi)$

$S_{D}(T, h)=S_{A}(T, h) \times(T /(2 \pi))^{2}$

Acceleration response spectrum, $S_{A}(T, h)$, given with the above formula is generally called as "Pseudo acceleration response spectrum." And, based on this formula, pseudo velocity response spectrum, $S_{V}(T, h)$, and pseudo displacement response spectrum, $S_{D}(T, h)$, are estimated by the following.

Figure 1 shows the conceptual figures for pseudo response spectrum, where $A=F_{h} G_{A} R_{A} A_{0}$ and $V=F_{h} G_{V} R_{V} V_{0}$, respectively.

As an earthquake response is different by floor, the following formulas using participation function are also introduced in order to estimate response values of respective floors. Here, $A_{j}, V_{j}, D_{j}$ are peak response acceleration, peak response velocity, and peak response displacement for the $j$ th-floor respectively. And, $\beta_{i} u_{j}$ is participation function of $i$ th-mode and $j$ th-floor which is to specify amplification of the earthquake response values for the $j$ th-floor in the $i$ th-mode.

$$
\begin{aligned}
& A_{j}=\sqrt{\sum_{i=1}^{n}\left(\beta_{i} u_{j} \times S_{A}\left(T_{i}, h\right)\right)^{2}} \\
& V_{j}=\sqrt{\sum_{i=1}^{n}\left(\beta_{i} u_{j} \times S_{V}\left(T_{i}, h\right)\right)^{2}} \\
& D_{j}=\sqrt{\sum_{i=1}^{n}\left(\beta_{i} u_{j} \times S_{D}\left(T_{i}, h\right)\right)^{2}}
\end{aligned}
$$




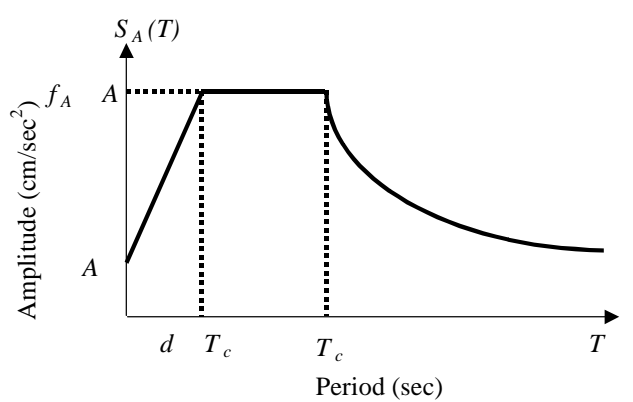

(a) pseudo acceleration response spectrum

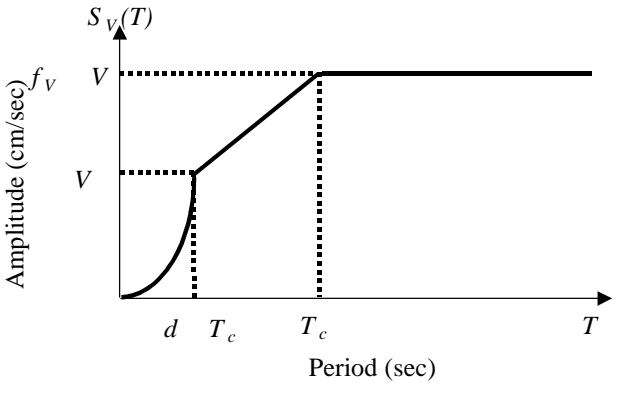

(b) pseudo velocity response spectrum

Figure 1 Image of pseudo response spectrum.

\section{Prediction Model of Functional Failure Probability for Sprinkler System}

As stated earlier, there could be functional failure on various fire protection systems at an earthquake, and most of these failures are likely to occur in the water suppression systems such as sprinkler system. The water suppression system does not perform its proper function as a whole system if whichever part goes wrong, because every part of these systems is linked with piping network, which should keep a certain level of water pressure. In this paper, therefore, we consider the failure probability of sprinkler system as a representative case for active fire protection systems as well as the most dominant element to be addressed.

The prediction model of failure probability of sprinkler system can be constructed based on a fault tree of seismic-induced damage on each part of sprinkler systems such as water tank, pump, vertical piping, horizontal piping, and sprinkler heads. For each part, considering the experiences of damages caused by past earthquakes, the dominant modes of functional failure are identified. Then, the probability of damage of each part can be given as a function of intensity of input earthquake motion. Also, the probability of failure as a whole sprinkler system is estimated from the probability of damage of each part. The following illustrations show the concept mentioned above for sprinkler systems for example. (See Figure 2, Figure 3)

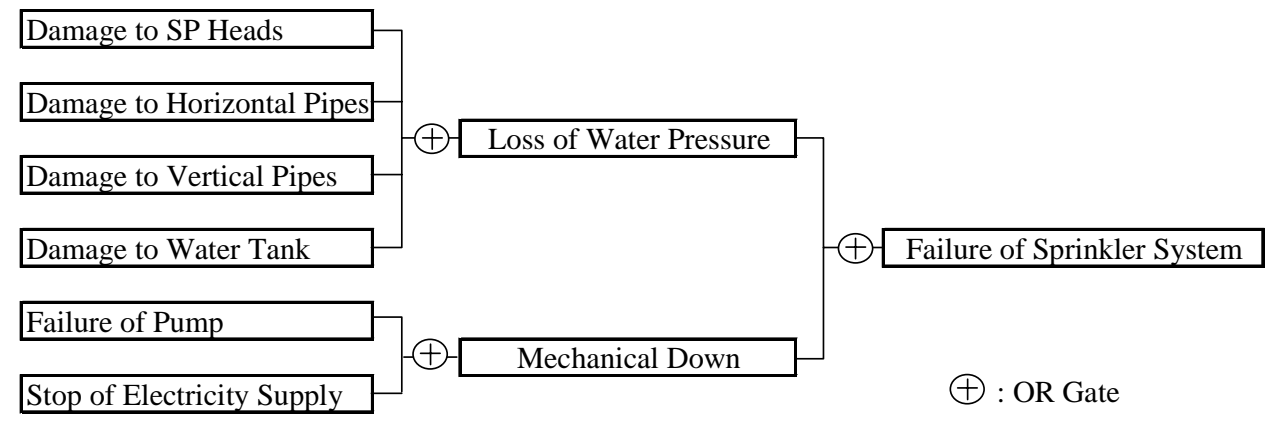

Figure 2 Fault Tree for Failure of Sprinkler System as a Whole. 


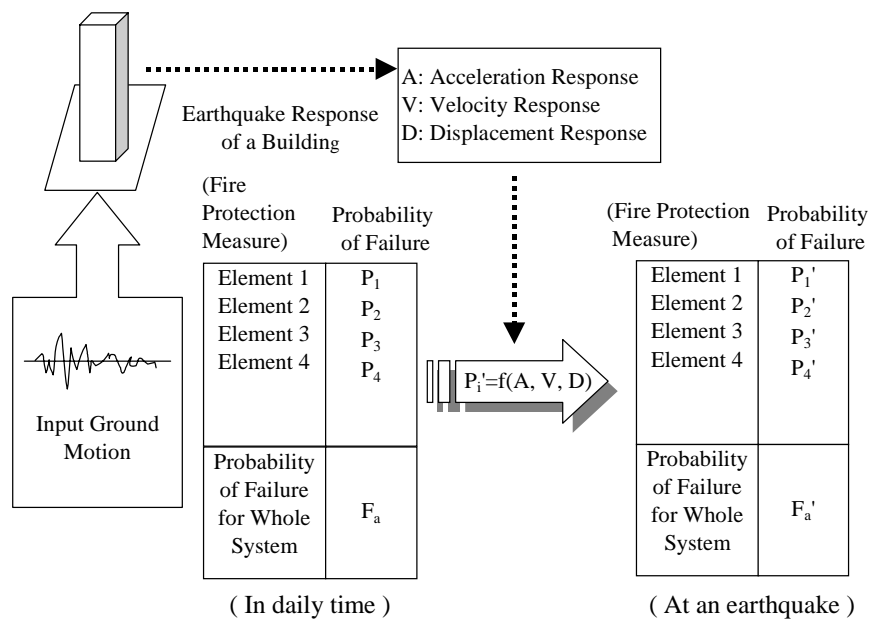

Figure 3 Concept of prediction model of functional failure for Sprinkler System .

By the way, even in normal use, there is a certain probability of functional failure of fire protection systems caused by maintenance problems. Therefore, the probability of functional failure of sprinkler system due to an earthquake is obtained by the product of the failure probability in normal use and the failure probability caused by an earthquake, which is estimated as a function of earthquake response velocity. For the part $i$ of sprinkler system, the failure probability at an earthquake is expressed as the following.

$P_{s i}=f_{i}(v) \square P_{d i}$

where,

$P_{s i}:$ Probability that part $i$ of sprinkler system does not operate at an earthquake.

$f_{i}(v)$ : Seismic-induced failure function for part $i$.

$v$ : Earthquake response velocity. $(\mathrm{cm} / \mathrm{sec})$

$P_{d i}$ : Failure probability in daily time.

There are two kinds of levels required for seismic-proof design of a building by the Building Codes in Japan. As to the respective levels, a standard value of response velocity as an input of earthquake motion is given for seismic-proof design in $25 \mathrm{~cm} / \mathrm{sec}$ for the grade 1 and $50 \mathrm{~cm} / \mathrm{sec}$ for the grade 2 . In consideration of the relation to seismic-proof design of a building, the criteria for dividing the levels of failure probability of sprinkler system is given here using the above values and the seismic-induced failure function $f_{i}(v)$ for pipes and heads is defined corresponding to response velocity as shown in Table 2 . The values of failure probability in this table are estimated based on the data from the investigation report [3] on the Kobe earthquake by Osaka City Fire Department.

Table 2 Failure Probability of Sprinkler System to Earthquake Response Velocity.

\begin{tabular}{|c|c|c|}
\hline Response velocity : & \multicolumn{2}{|c|}{ Probability of failure $(\%)$} \\
\cline { 2 - 3 }$V_{r}(\mathrm{~cm} / \mathrm{sec})$ & Pipes & Heads \\
\hline $0<V_{r} \leqq 25$ & 20 & 20 \\
$25<V_{r} \leqq 50$ & 20 & 30 \\
$50<V_{r}$ & 30 & 40 \\
\hline
\end{tabular}


Sprinkler system can not achieve its expected function as a whole system when any part of the system loses the function. Therefore, probability of functional failure of sprinkler system is calculated as a kind of series system of failure probability of each part $\left(P_{s i}\right)$.

$$
F_{S P}=1-\prod_{i=1}^{k}\left(1-P_{S i}\right)
$$

where,

$F_{s p}$ : Probability of functional failure of sprinkler system as a whole.

$k:$ Number of parts which consist of sprinkler system.

$P_{s i}$ : Probability that part i of sprinkler system does not operate at an earthquake.

\section{Damage to Fire and Non-Fire Compartments}

There are very little data from investigation available for predicting the damage of compartments caused by earthquakes. On the other hand, the assumed criteria on the damage to fire resistance time of compartments according to relative story displacement are described in the design guideline [7] of compartments issued by the Architectural Institute of Japan. Therefore, we put the reducing ratio of fire resistance time of fire and non-fire compartments depending on the relative story displacement after the above criteria as shown in Table 3.

Table 3 Reducing Ratio of Fire Resistance Time to Relative Story Displacement.

\begin{tabular}{|c|c|c|}
\hline $\begin{array}{c}\text { Relative story } \\
\text { displacement : } \\
D_{r}\end{array}$ & $\begin{array}{c}\text { Reducing ratio of fire resistance time to normal } \\
\text { condition }\end{array}$ & $\begin{array}{c}\text { Fire compartments } \\
(60 \mathrm{~min} .)\end{array}$ \\
\cline { 2 - 3 } & 1.0 & $\begin{array}{c}\text { Other compartments } \\
(30 \mathrm{~min} .)\end{array}$ \\
\hline $0<D_{r} \leqq 1 / 400$ & 1.0 & 1.0 \\
$1 / 400<D_{r} \leqq 1 / 300$ & 0.5 & 0.5 \\
$1 / 300<D_{r}$ & & 0.0 \\
\hline
\end{tabular}

\section{Seismic Impact to Fire Protection Action by Security Staff}

Fire protection action by security staff must be affected by earthquake motion, but the analytical estimate of how such response action is impacted according to the seismic intensity has not been done yet. At present, therefore, based on the existing explanatory description of human response condition corresponding to the JMA seismic intensity scale, we put the reducing ratio of execution probability of fire protection action by security staff in usual time depending on response acceleration as shown in Table 4.

Table 4 Reducing Ratio of Probability of Fire Protection Action by Security Staff.

\begin{tabular}{|c|c|}
\hline $\begin{array}{c}\text { Response acceleration : } \\
A_{r}\left(\mathrm{~cm} / \mathrm{sec}^{2}\right)\end{array}$ & $\begin{array}{c}\text { Reducing ratio of probability of fire } \\
\text { protection action to normal situation }\end{array}$ \\
\hline $0<A_{r} \leqq 100$ & 1.0 \\
$100<A_{r} \leqq 250$ & 0.5 \\
$250<A_{r}$ & 0.1 \\
\hline
\end{tabular}




\section{Conditions of Case Study}

We conducted a case study applying the tentative simplified assessment method to a model building to see how seismic-induced fire risk changes depending on the intensity of earthquake motion. The conditions and the floor plan of a model building for case study are shown in Table 5 and in Figure 4. And, the parameters on failure probability and reducing ratio of performance of fire protection systems and response action by security staff according to peak ground acceleration are shown in Table 6 . As stated earlier in this paper, we incorporated the failure probability of active and passive fire protection systems into the existing fire risk assessment model for usual fires [5] to estimate seismic-induced fire risk. In this model, the concept of fire phase transition is adopted to evaluate the probability of changing fire phases ( fire growth stages ) from one to another, which is derived from whether or not fire protection measures can be brought into effect within a certain critical time defined for each fire phase. The outcomes of fire risk by this model are cumulative probability of exceeding a fire phase and expected fire spread area in square meters, which is calculated with the exceeding probability of a fire phase. The classification of fire phases and critical conditions of fire phase transition together with corresponding fire protection measures are described in Table 7.

Table 5 Conditions of Case Study.

\begin{tabular}{|l|l|}
\hline Occupancy of building & Office \\
\hline Structure type of building & Steel Frame \\
\hline Number of floors & $20 \mathrm{floors}$ \\
\hline Floor height & $4.0 \mathrm{~m}$ \\
\hline Area of floor & $1,538 \mathrm{~m}^{2}$ \\
\hline Floor of fire origin & 5 th Floor \\
\hline Area of room of fire origin & $384.4 \mathrm{~m}^{2}$ \\
\hline Room height & $2.7 \mathrm{~m}$ \\
\hline Fire growth rate $\left(\alpha\right.$ in $\left.\mathrm{Q}=\alpha \mathrm{t}^{2}\right)$ & 0.05 \\
\hline Density of fire load & $30 \mathrm{~kg} / \mathrm{m}^{2}$ \\
\hline Soil type of the ground & Soil Type $-\mathrm{I}($ Hard Soil) \\
\hline $\begin{array}{l}\text { Peak ground acceleration: } \\
\text { Input earthquake motion }\end{array}$ & from 0 (Normal Condition) to $600\left(\mathrm{~cm} / \mathrm{sec}^{2}\right)$ \\
\hline
\end{tabular}

Table 6 Parameters of Failure Probability and Reducing Ratio of Performance of Fire Protection Systems and Fire Protection Action for Case Study.

\begin{tabular}{|c|c|c|c|c|c|c|}
\hline \multirow[b]{3}{*}{$\begin{array}{l}\text { Peak ground } \\
\text { acceleration } \\
\left(\mathrm{cm} / \mathrm{sec}^{2}\right)\end{array}$} & \multicolumn{5}{|c|}{ Fire Protection Systems } & \multirow{3}{*}{$\begin{array}{l}\text { Reducing ratio of } \\
\text { probability of fire } \\
\text { protection action by } \\
\text { security staff }\end{array}$} \\
\hline & \multicolumn{3}{|c|}{$\begin{array}{l}\text { Probability of functional } \\
\text { failure of sprinkler system }\end{array}$} & \multicolumn{2}{|c|}{$\begin{array}{l}\text { Reducing ratio of fire } \\
\text { resistance time }\end{array}$} & \\
\hline & Pipes & Heads & $F_{s p}$ & $\begin{array}{c}\text { Fire } \\
(60 \mathrm{~min} .) \\
* \\
\text { Compart } \\
\text { ments }\end{array}$ & $\begin{array}{c}\text { Other } \\
(30 \mathrm{~min} .)^{*} \\
\text { Compartme } \\
\text { nts }\end{array}$ & \\
\hline 0 & 0.0 & 0.0 & 0.03 & 1.0 & 1.0 & 1.0 \\
\hline 100 & 0.2 & 0.2 & 0.36 & 1.0 & 1.0 & 1.0 \\
\hline 200 & 0.2 & 0.3 & 0.44 & 1.0 & 1.0 & 0.5 \\
\hline 300 & 0.2 & 0.3 & 0.44 & 1.0 & 1.0 & 0.5 \\
\hline 400 & 0.3 & 0.4 & 0.58 & 1.0 & 1.0 & 0.5 \\
\hline 500 & 0.3 & 0.4 & 0.58 & 1.0 & 0.5 & 0.1 \\
\hline 600 & 0.3 & 0.4 & 0.58 & 0.5 & 0.0 & 0.1 \\
\hline
\end{tabular}

*Fire resistance time here is specified for this case study. 


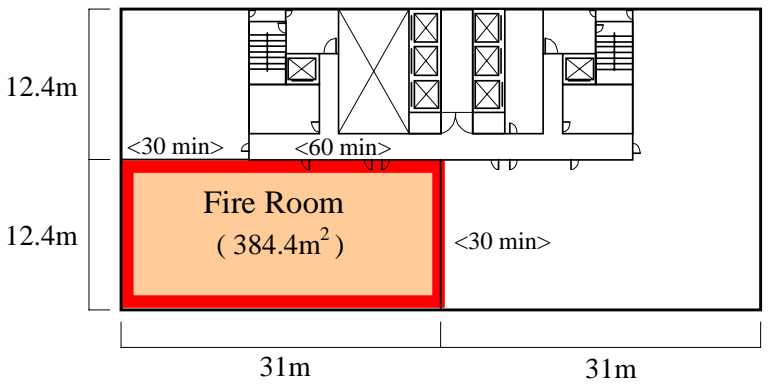

*Fire resistance time of walls and doors is indicated in $\langle>$.

Figure 4 Floor Plan of a Building for Case Study.

Table 7 Classification of Fire Phases and Critical Conditions of Fire Phase Transition.

\begin{tabular}{|c|c|c|c|c|}
\hline $\begin{array}{l}\text { Fire } \\
\text { Phase }\end{array}$ & Image of Fire Phase & $\begin{array}{c}\text { State of } \\
\text { Period of Fire Phase }\end{array}$ & $\begin{array}{c}\text { Threshold of } \\
\text { Fire Phase Transition }\end{array}$ & $\begin{array}{c}\text { Fire Protection Equipment and } \\
\text { Actions to } \\
\text { Prevent Fire Phase Transition }\end{array}$ \\
\hline $\begin{array}{c}\text { Phase } \\
1\end{array}$ & Fire Room & $\begin{array}{l}\text { Fire occurs and is growing up. } \\
\text { It is able to be extinguished by } \\
\text { fire security staffs. }\end{array}$ & $\begin{array}{c}\text { Min. }\left(T_{L F}, T_{950}, T_{P h 2}\right) \\
\\
\mathrm{T}_{\mathrm{LF}}: \text { Fire Flame Reaches } \\
\text { Ceiling of Fire } \\
T_{950}: \text { Heat Release } \\
\text { Reaches } 950 \mathrm{~kW} \\
\end{array}$ & Fire Extinguisher * \\
\hline $\begin{array}{c}\text { Phase } \\
2\end{array}$ & $\mathrm{Fi}$ & $\begin{array}{l}\text { Fire is growing and not able to } \\
\text { be extinguished by fire } \\
\text { Hot smoke layer forms under } \\
\text { the ceiling of the fire room. }\end{array}$ & \begin{tabular}{|c|}
$T_{P h 2}$ \\
Limitation of the \\
Egress Time of Fire Room \\
$\begin{array}{c}\text { Smoke Layer Height } \\
<\text { Human Height }\end{array}$ \\
\end{tabular} & $\begin{array}{c}\text { Fire Hydrant * } \\
\text { Sprinkler System * }\end{array}$ \\
\hline $\begin{array}{c}\text { Phase } \\
3\end{array}$ & Adjacent Room & $\begin{array}{l}\text { Fire is growing and people } \\
\text { stay in the fire room. } \\
\text { Temperature of the fire room } \\
\text { is growing up. }\end{array}$ & $\begin{array}{l}T_{P h 3} \\
\text { Temperature of Fire } \\
\text { Reaches } 600{ }^{\circ} \mathrm{C} \text { or } 300 \\
\text { Reaches } \\
600{ }^{\circ} \mathrm{C} \text { (incombustible) } \\
300^{\circ} \mathrm{C} \text { ( combustible) }\end{array}$ & $\begin{array}{l}\text { Closing the doors of the Fire Room } \\
\text { Starting Smoke Exhaust System * } \\
\text { Turning off Air Conditioning }\end{array}$ \\
\hline $\begin{array}{c}\text { Phase } \\
4\end{array}$ & Fire Room Adjacent Room & $\begin{array}{l}\text { Fire is fully developed } \\
\text { but is confined in the fire room. }\end{array}$ & \begin{tabular}{|c|}
$T_{P h 4}$ \\
Fire Resistance Time * of \\
Walls and Doors \\
Surrounding Room of \\
Fire Origin
\end{tabular} & Fire Brigade Action * \\
\hline $\begin{array}{l}\text { Phase } \\
5\end{array}$ & $\begin{array}{l}\text { Fire Room Corridor } \\
\text { Adjacent Room }\end{array}$ & Fire spreads out to adjacent & \begin{tabular}{|c|}
$T_{P h 5}$ \\
Fire Resistance Time * of \\
Compartment \\
(Fire Compartment) of \\
Fire Origin
\end{tabular} & Fire Brigade Action * \\
\hline
\end{tabular}

* These items are influenced by earthquake motion in this case study. 


\section{Results and Discussion}

As an example from the results of case study, Figure 5 shows the changes of probability of exceeding fire phases for respective peak ground acceleration. As seen in the figure, the probability of exceeding fire phases becomes larger as the peak ground acceleration (hereafter PGA: in $\mathrm{cm} / \mathrm{sec}^{2}$ ) is larger. Differences in excess probability of fire phase 2 seen in the figure is due to both functional failure of sprinkler system and decreasing probability of response actions by security staff according to the PGA. On the other hand, the difference in excess probability of fire phase 4 between " 500 and under" and "600" in PGA is mainly due to the drastic change of performance of compartments at this critical point. But, in this case study, we set the premise that professional fire brigades should arrive at a fire scene in the stage of fire phase 5 , which is fire spread beyond a room of fire origin, so the probability of exceeding fire phase 5 is close to zero.

Figure 6 shows the change of "Expected Fire Spread Area" (hereafter EFSA: in $\mathrm{m}^{2}$ ) as a function of PGA for two cases as the one that sprinkler system is not seismic-proof and same as usual condition ( solid line ) and the other that sprinkler system is changed to be seismic-proof ( dotted line ).

As for the former case ( solid line ), the increase of EFSA at 100 of PGA is derived only from failure of sprinkler system, but the increase of EFSA from 200 to 400 in PGA is due to both failure of sprinkler system and decreasing probability of response actions by security staff. Then, the sharp increase of EFSA from 500 to 600 in PGA is derived from additional influence by reduced performance of compartments as well as the above two factors. To compare with EFSA from 500 in PGA, the value of EFSA at 100 in PGA is relatively small. However, if the premise, that fire brigades arrive in the stage of fire phase 5 , is changed to be more unfavorable and/or a seismic-induced fire occurs at night when security staffs are absent, the profile of EFSA in Figure 6 would be different and the values of EFSA would be probably much larger.

However, as seen in Figure 6, the data of the latter case ( dotted line ) demonstrates the significance of seismic-proof design even alone for sprinkler system in mitigating fire risk at an earthquake, because sprinkler system suppresses a fire in its very early stage of fire growth. In Japan, a strong earthquake occurs fairly frequently, where the seismic intensity is around level 6 in JMA (Japan Meteorological Agency) scale that is about $250 \mathrm{~cm} / \mathrm{sec}^{2}$ to $400 \mathrm{~cm} / \mathrm{sec}^{2}$ in ground surface acceleration. In this condition for example, if a fire occurs, the EFSA for the case of seismic-proof sprinkler system ( dotted line ) is one tenth or less than the EFSA for the case of non seismic-proof sprinkler system ( solid line ).

Like the above examples of results of case study, we can evaluate and discuss the potential fire risk according to given conditions such as size and type of buildings, installed fire protection systems, and the intensity of input earthquake motion using the seismic-induced fire risk assessment method. Also, we can examine the effect of seismic-proof design of fire protection systems on the potential fire risk at an earthquake. 

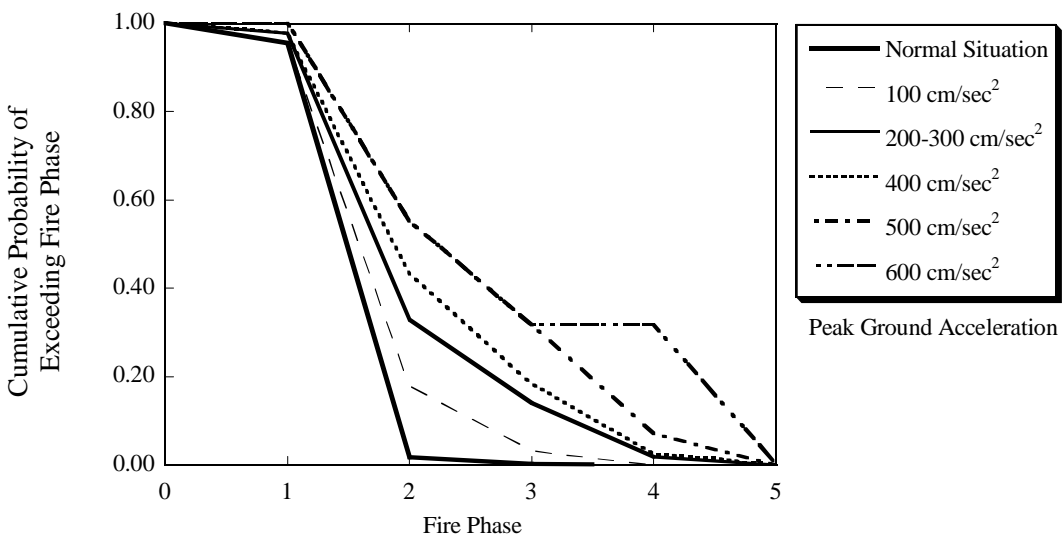

Peak Ground Acceleration

Figure 5 Cumulative Probability of Exceeding Fire Phases for Respective Peak Ground Acceleration.

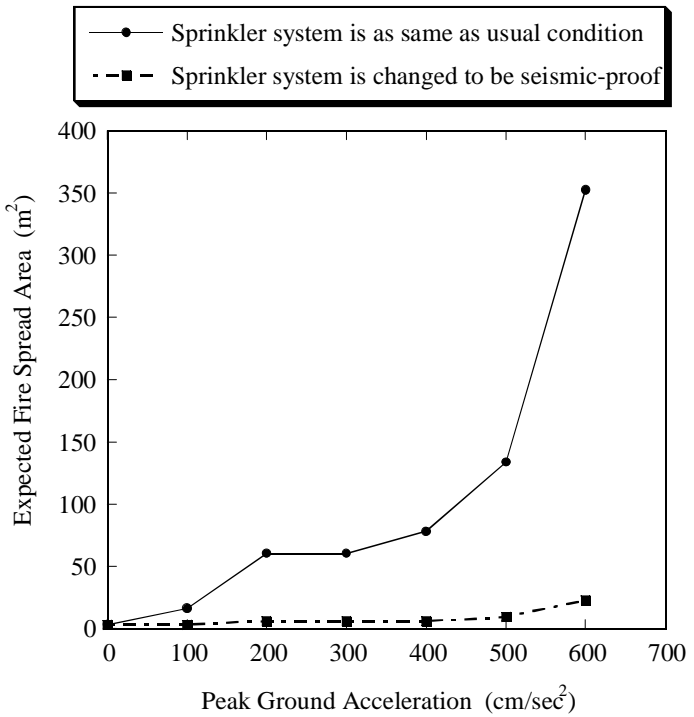

Figure 6 Expected Fire Spread Area as a Function of Peak Ground Acceleration.

\section{Concluding Remarks}

We have developed the prototype of a seismic-induced fire risk assessment method to evaluate fire risk according to conditions such as size and type of buildings, installed fire protection systems, and the intensity of input earthquake motion. In this paper, we described the outline of the framework and discuss the examples of results from case study applying a tentative simplified model. The following were obtained from our study, although limited in certain conditions for the case study in this paper. 
1. Sprinkler system can not achieve its expected function as a whole system when any part of the system loses the function. Therefore, probability of functional failure of sprinkler system is calculated as the reliability of a series system.

2. The probability of exceeding fire phases becomes larger as the peak ground acceleration is larger. The impact on fire risk of functional failure of sprinkler system and failure of response actions by security staff appears in the early stage of fire growth and influences greatly consequent excess probability in higher fire phases. On the other hand, failure of performance of compartments is likely to occur from $500 \mathrm{~cm} / \mathrm{sec}^{2}$ of peak ground acceleration and affects the probability of fire spread beyond the room of fire origin.

3. Seismic-proof design even alone for sprinkler system has great effect in mitigating fire risk at an earthquake. When the seismic intensity level is 6 in JMA (Japan Meteorological Agency) scale that is about $250 \mathrm{~cm} / \mathrm{sec}^{2}$ to $400 \mathrm{~cm} / \mathrm{sec}^{2}$ in peak ground acceleration, the expected fire spread area for the case of seismic-proof sprinkler system is only one tenth or less than that for the case of non seismic-proof sprinkler system.

In the last, the profile of expected fire spread area in Figure 6 can be deemed as a kind of "Fragility Curve" of a building in terms of vulnerability to seismic fires along with peak ground acceleration, which represents fire hazard for a given fire scenario specified in Table 5. To really make the method to be fire risk assessment, it will be needed to incorporate fire ignition incidence according to seismic intensity as an occurrence probability to be multiplied with estimated fire hazard for a specific fire scenario. Also, there are assumptions and incomplete parts in the current method. Therefore, this seismic-induced fire risk assessment method should be refined and upgraded for the future.

\section{References}

1. The Marine and Fire Insurance Association of Japan, "Study Report on Reliability of Fire Protection Systems at an Earthquake," 1995.

2. Kobe City Fire Department, "Investigation Report on Damages to Fire protection Systems Caused by the Hanshin-Awaji Earthquake in Kobe," 1995.

3. Osaka City Fire Department, "Investigation Report on Damages to Fire protection Systems Caused by the Hanshin-Awaji Earthquake in Osaka," 1995.

4. The Architectural Institute of Japan, "Investigation Report on the 1995 Hanshin-Awaji Earthquake-Vol.6 (Fire and Information System)," 1998.

5. Yashiro, Y., Ebihara, M. and Notake, H., "Fire safety Design and Fire Risk Analysis Incorporating Staff Response in Consideration of Fire Progress Stage," The Paper for the 15th UJNR Meeting, 2000.

6. The Architectural Institute of Japan, "Guidelines and Commentary on Loads on Buildings," 1993.

7. The Architectural Institute of Japan, "Guidebook for Design and Practice of Fire Compartment," 1990. 